\title{
Mass clinical survey as a possible population strategy for the better control of hypertension in Japan
}

\author{
Kouichi Tamura ${ }^{1} \cdot$ Takahiro Yamaji $^{1} \cdot$ Kengo Azushima $^{1,2} \cdot$ Hiromichi Wakui $^{1}$
}

Received: 1 December 2019 / Accepted: 3 December 2019 / Published online: 12 February 2020

(c) The Japanese Society of Hypertension 2020

During the past century, human life expectancy has nearly doubled globally, increasing by more years than it did in all previous millennia combined [1]. Nevertheless, aging is a major risk factor for multiple noncommunicable diseases, such as cancers and cardiovascular, metabolic and neurodegenerative conditions, including hypertension and diabetes, which are the most common causes of premature death and morbidity. In addition, all of these pathological conditions require extensive long-term care and exert a critical impact on healthcare costs, productivity, and growth [1]. In particular, hypertension is one of the most pressing public health challenges. Hypertension is recognized as the biggest contributor to the global burden of disease [2]. Globally, in 2015, 1.13 billion adults had raised blood pressure (defined as a systolic blood pressure of $140 \mathrm{mmHg}$ or higher or a diastolic blood pressure of $90 \mathrm{mmHg}$ or higher) [3]. Hypertension is highly prevalent worldwide and is a major cause of strokes (such as cerebral infarction, cerebral hemorrhage, and subarachnoid hemorrhage), heart diseases (such as coronary artery disease, cardiac hypertrophy, and heart failure), kidney diseases (such as nephrosclerosis and end-stage kidney disease), and macrovascular diseases (such as aortic dissection and peripheral artery disease) [4]; thus, hypertension plays a key role in the progression of the pathological linkage between cardiovascular and kidney diseases (Fig. 1). Therefore, a primary aim of hypertension management is to present standard management strategies and evidence to all medical workers to provide appropriate treatment to patients with

Kouichi Tamura

tamukou@med.yokohama-cu.ac.jp

1 Department of Medical Science and Cardiorenal Medicine, Yokohama City University Graduate School of Medicine, Yokohama, Japan

2 Cardiovascular \& Metabolic Disorders Program, Duke-NUS Medical School, Singapore, Singapore hypertension, most frequently encountered by clinicians/ practitioners in daily practice, for the prevention of the onset/progression of hypertension complications in the brain/heart/kidney by blood pressure control [5]. In Japan, a 2010 survey estimated that there were 43 million patients with hypertension, with only $\sim 15-30 \%$ controlling their BP below 140/90 $\mathrm{mmHg}$ [6]. Because of the large number of individuals with hypertension and the poor control rate, hypertension is one of the leading causes of death (next to smoking) in Japan [7].

To improve hypertension management, a series of hypertension guidelines have been developed and updated regularly by various societies. For example, in recent years, overseas guidelines have been developed by the American College of Cardiology/American Heart Association and the European Society of Cardiology/European Society of Hypertension [8, 9]. These guidelines have created a considerable shift in the landscape of hypertension management [10]. In Japan, the Japanese Society of Hypertension (JSH) published its first guideline in 2000 (JSH 2000), which has been revised every 4 or 5 years, and the most updated version was released in April 2019 as the JSH Guidelines for the Management of Hypertension 2019 (JSH 2019) [11]. Even in the recently published JSH 2019 guidelines, only $50 \%$ of individuals are treated, and $\sim 25 \%$ are controlled at a target BP level below 140/90 $\mathrm{mmHg}$ [11]. Concerning this important issue, several reasons were reported. For example, analyses using a Japanese claims database indicated that poor adherence to antihypertensive treatment was associated with a higher number of drugs and a higher number of pills prescribed [12]. Furthermore, physician problems, including the inappropriate use of antihypertensive drugs, are also involved in treatment resistance in many cases. The state in which medical workers, including physicians, do not comply with the necessity of enhancing antihypertensive treatment according to guidelines is termed "clinical inertia," which is a great barrier to the achievement of target BP control in patients with hypertension [11]. 
Fig. 1 A population strategy by mass survey would hopefully resolve the "clinical inertia" to improve BP control in patients with hypertension and to inhibit the "cardiovascular and renal continuum"

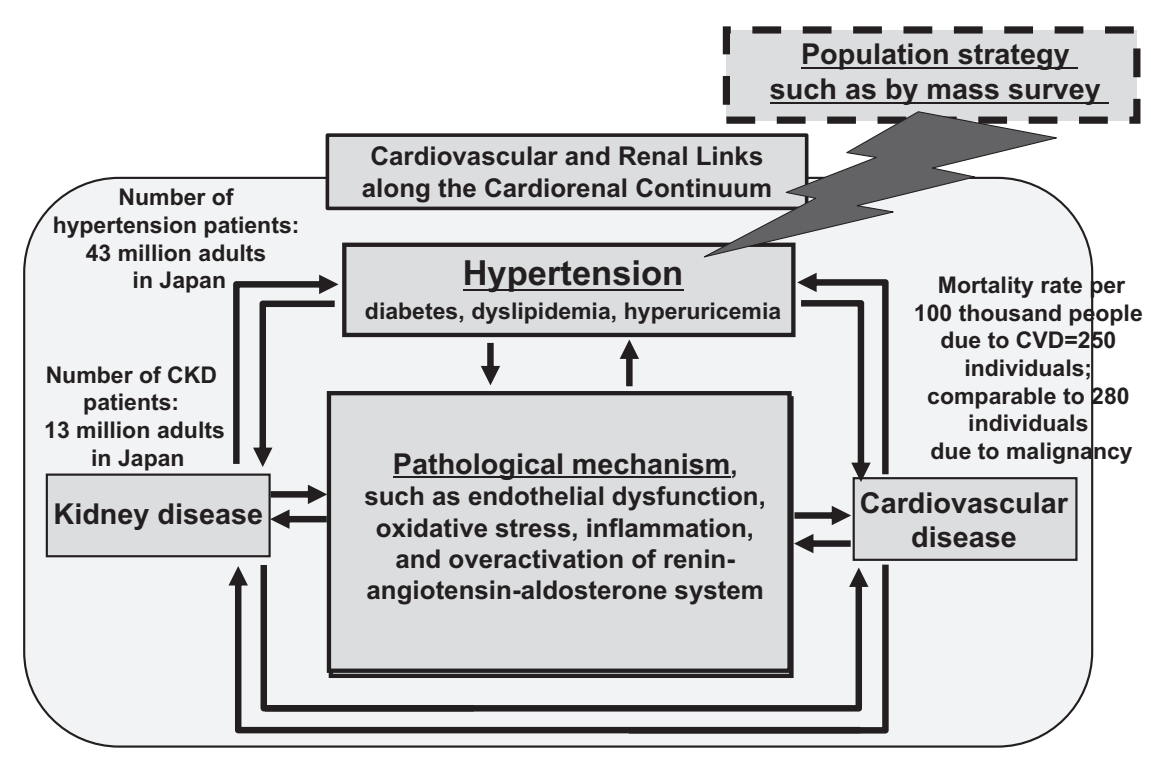

Thus, despite the remarkable advances in the diagnosis/ treatment of hypertension, countermeasures against hypertension are still insufficient, and this status is called the "hypertension paradox." In addition, it has recently been suggested that measures against lifestyle-based diseases that are based on cognitive behavioral therapy are important. Concerning the treatment of hypertension, the nationwide plan of the promotion of actions by extensively disseminating the awareness that the onset/progression of illness can be prevented does not seem to have been sufficiently achieved. To achieve this, improvement/reform in both patients and healthcare providers may be required, and further overcoming the clinical inertia is required by employing composite attempts in accordance with guidelines. Thus, establishing a guidance strategy, including cognitive behavioral therapy administered by a multidisciplinary team, is essential. In this issue of Hypertension Research, Yoshida et al. analyzed data from a large-scale and web-based survey (PARADOX) to gain insight into this paradox from the physicians' perspective, with results categorized according to specialty (i.e., with or without certification by the JSH), institution type, gender, and age [13]. The authors showed that the provision and perceptions of education differed between physician categories. They also indicated that nonspecialists were less likely to provide adequate guidance on lifestyle modifications, possibly due to their uncertainty in understanding treatment guideline recommendations compared with specialist physicians. The results presented in the manuscript are interesting and important for understanding the up-to-date situation of the "hypertension paradox" in Japan. In addition, a broader employment of such a population strategy by mass survey would hopefully resolve the "clinical inertia" to improve BP control in patients with hypertension and to inhibit the "cardiovascular and renal continuum" (Fig. 1), and further clinical research is expected to seek the answer.

Acknowledgements This work was supported by grants from the Yokohama Foundation for Advancement of Medical Science; a Uehara Memorial Foundation grant; Grants-in-Aid for Scientific Research from the Japan Society for the Promotion of Science; grants from Senshin Medical Research, the Banyu Life Science Foundation International, and the Salt Science Research Foundation (19C4); and a grant-in-aid from the Cardiovascular Research Fund, Tokyo, Japan. This research was also supported by a grant from the Strategic Research Project of Yokohama City University, Japan Agency for Medical Research and Development (AMED); a Yokohama City University research grant "KAMOME Project"; and by TR-SPRINT (Translational Research program; Strategic PRomotion for practical application of INnovative Medical Technology) from AMED.

\section{Compliance with ethical standards}

Conflict of interest The authors declared that they have no conflict of interest.

Publisher's note Springer Nature remains neutral with regard to jurisdictional claims in published maps and institutional affiliations.

\section{References}

1. Dzau VJ, Inouye SK, Rowe JW, Finkelman E, Yamada T. Enabling healthful aging for all-The National Academy of Medicine Grand Challenge in Healthy Longevity. N Engl J Med. 2019;381:1699-701.

2. Dzau VJ, Balatbat CA. Future of hypertension. Hypertension. 2019;74:450-7.

3. Collaboration NCDRF. Worldwide trends in blood pressure from 1975 to 2015: a pooled analysis of 1479 population-based measurement studies with 19.1 million participants. Lancet. 2017;389:37-55 
4. Tamura K, Waki K, Kawai Y, Ueda E, Ishii T, Wakui H. Possible interesting link between dipping status and morning surge for subclinical target organ damage in hypertension. J Clin Hypertens. 2019;21:1295-7.

5. Wang JG, Liu L. Global impact of 2017 American College of Cardiology/American Heart Association Hypertension Guidelines: a perspective from China. Circulation. 2018;137:546-8.

6. Miura K, Nagai M, Ohkubo T. Epidemiology of hypertension in Japan: where are we now? Circ J. 2013;77:2226-31.

7. Ikeda N, Inoue M, Iso H, Ikeda S, Satoh T, Noda M, et al. Adult mortality attributable to preventable risk factors for noncommunicable diseases and injuries in Japan: a comparative risk assessment. PLoS Med. 2012;9:e1001160.

8. Whelton PK, Carey RM, Aronow WS, Casey DE Jr, Collins KJ, Dennison Himmelfarb C, et al. 2017 ACC/AHA/AAPA/ABC/ ACPM/AGS/APhA/ASH/ASPC/NMA/PCNA Guideline for the prevention, detection, evaluation, and management of high blood pressure in adults: a report of the American College of Cardiology/American Heart Association Task Force on Clinical Practice Guidelines. Hypertension. 2018;71:e13-e115.

9. Williams B, Mancia G, Spiering W, Agabiti Rosei E, Azizi M, Burnier M, Authors/Task Force M. et al. 2018 ESC/ESH
Guidelines for the management of arterial hypertension: The Task Force for the management of arterial hypertension of the European Society of Cardiology and the European Society of Hypertension: The Task Force for the management of arterial hypertension of the European Society of Cardiology and the European Society of Hypertension. J Hypertens. 2018;36:1953-2041.

10. Hirawa N, Umemura S, Ito S. Viewpoint on guidelines for treatment of hypertension in Japan. Circ Res. 2019;124:981-3.

11. Umemura S, Arima H, Arima S, Asayama K, Dohi Y, Hirooka Y, et al. The Japanese Society of Hypertension Guidelines for the management of hypertension (JSH 2019). Hypertens Res. 2019;42:1235-481.

12. Ishida T, Oh A, Hiroi S, Shimasaki Y, Nishigaki N, Tsuchihashi $\mathrm{T}$. Treatment patterns and adherence to antihypertensive combination therapies in Japan using a claims database. Hypertens Res. 2019;42:249-56

13. Yoshida T, Nishigaki N, Saita S, Shimasaki Y, Hasebe N. Perspectives of patients and physicians regarding hypertensive management from an online survey for excellence: a subanalysis of the PARADOX study by physician categories. Hypertens Res. 2020. https://doi.org/10.1038/s41440-019-0365-9. [Epub ahead of print]. 